
региональных и международных исследований ДВФУ (г. Владивосток)

Электронная почта: gritcenko.ra@dvfu.ru

\title{
Оценка мягкой силы России в КНР, Японии и Южной Корее при помощи качественных методов (на примере глубинного интервью с иностранными студентами ДВФУ)
}

\section{УДК 327.8}

международные отношения,

мягкая сила,

Северо-Восточная

Азия,

высшее образование, привлекательность

России в СВА,

глубинное интервью с иностранцами
Для иитирования:

Гриценко Р. А. Оценка мягкой силы России в КНР, Японии и Южной Корее при помощи качественных методов (на примере глубинного интервью с иностранными студентами ДВФУ) // Известия Восточного института. 2020. № 3. C. $70-78$. doi: dx.doi.org/10.24866/2542 $1611 / 2020-3 / 70-78$ doi: dx.doi.org/10.24866/2542-1611/2020-3/70-78

В данной статье автор анализирует представления о России как самих японских, китайских и южнокорейских студентов, обучающихся в Дальневосточном федеральном университете, так и их окружения. Основной метод исследования проведения глубинного интервью с самими студентами. По результатам интервью сформировано несколько выводов относительно состояния мягкой силы РФ в этой стране, но также автор приходит к нескольким общим выводам: обучение в России положительно влияет на мнение о стране, но при этом в Японии и Южной Корее весьма смутное представление о России и необходимо развернуть активную деятельность в данном направлении.

В силу ряда обстоятельств с 2014 года у России весьма напряжённые взаимоотношения с западными партнерами, и взаимовыгодное политическое и экономическое сотрудничество с ними затруднено. Также последние несколько лет экономический и политический центр мира постепенно смещается из Европы и Атлантики в Восточную Азию. При этом для эффективного развития Дальнего Востока России необходим иностранный капитал, прежде всего, стран Северо-Восточной Азии (СВА). Китай представляет собой серьезную силу на международной арене и является второй экономикой мира. Япония - третья страна мира по объёму ВВП, а Республика Корея - одиннадцатая [5]. России для дальнейшего развития необходимо тесное политическое и экономическое сотрудничество с ведущими странами Северо-восточной Азии. На данный момент нельзя сказать, что Россия играет серьёзную роль в АТР и закрепила свои позиции в регионе. В Северо-Восточной Азии до сих пор не существует единой архитектуры безопасности, а также, в отличие от Европы или Юго-Восточной Азии, института, который регулирует международные отношения в регионе. Отношения в СВА выстраиваются на основе двусторонних взаимосвязей между государствами в условиях, когда у всех государств региона существует недоверие и исторические претензии друг к другу. Такая ситуация оставляет для России возможность включиться в качестве «третьей стороны» в международные отношения в регионе.

Эти причины заставляют Россию обратить взгляд на Восток и быть заинтересованной в формировании положительного и привлекательного для стран СВА образа. Тот факт, что Россия не имеет напряжённых отношений и серьёзных противоречий 
в сфере политический ценностей со странами АТР, делает возможным и перспективным использование инструментов мягкой силы.

Несмотря на то, что до сих пор идут споры вокруг содержания понятия мягкая сила [1, с.59; 4, с.27-29], привлекательность высшего образования страны признается важной составляющей мягкой силы государства со значительным потенциалом.

В Дальневосточном федеральном университете обучается значительное количество иностранных студентов, в том числе из Японии, КНР и Республики Корея. Также ДВФУ является единственным ВУЗом России - членом престижной Ассоциации азиатско-тихоокеанских университетов (APRU) [3]. Поэтому мы решили проанализировать, как процесс получения высшего образования в России повлиял на представления иностранных студентов о России, какое впечатление сложилось у них о нашей стране, какое мнение о России они транслируют на свою родину и что думают их соотечественники о России.

Для этого была проведена серия интервью с гражданами данных стран, которые являются студентами Дальневосточного федерального университета. В качестве респондентов выступили шесть человек: два гражданина Республики Корея, два представителя Японии и два гражданина КНР. Каждый из них провёл разное количество времени в России и, конечно, это сказалось на отношении к стране. Также необходимо учитывать то обстоятельство, что эти студенты уже приехали в Россию обучаться, следовательно, они представляют собой более лояльных респондентов, которые в какой-то степени уже попали под влияние мягкой силы России.

Респондентам были заданы следующие вопросы:

1. Почему вы приехали учиться в Россию, почему выбрали для изучения именно русский язык?

2. Какие ассоциации у вас вызывает Россия?

3. Что вам нравится в России? А что не нравится?

4. Сколько лет вы уже находитесь в России? Изменилось ли ваше мнение о России за это время? Если да, то как? Что вы знали о России до того, как приехали сюда?

5. Нравится ли вам Россия? Что вы думаете о России?

6. Вам нравится то образование, которое вы получаете?

7. Хотелось ли бы вам остаться в России работать, жить?

8. Что вы рассказываете своим знакомым об обучении и жизни в России?

9. Каково отношение к России среди ваших соотечественников, не живущих в России?

10. Каково отношение к России среди ребят из Вашей страны, которые также обучаются в РФ?

11. Когда вы разговариваете о России с вашими друзьями/родственниками, обычно на какие темы вы говорите? (политика Путина, туризм в Россию, новости из России, какие-то особенности нашей культуры и т.д.)

12. Как вы оцениваете отношения между Россией и Вашей страной?

13. Отличается ли в вашей стране мнение о России у молодежи и старшего поколения? Если да, то как?

14. Относитесь ли вы к России с симпатией?

Все вопросы можно разделить на несколько блоков.

Общее отношение респондента к России. Вопросы 2, 3, 5, 14. Ответы на эти вопросы позволят понять, как в общем и целом респондент относится к России, преимущественно на эмоциональном 
уровне. Иными словами, какое воздействие в целом на гражданина иностранной страны оказала мягкая сила России, в том числе и за время его пребывания в России.

Отношение респондента к отдельным аспектам мягкой силы России. Вопросы 1, 4, 6, 7, 12. Ответы на эти вопросы позволяют сделать вывод о том, что именно повлияло на отношение респондента к России. Какие элементы оказали положительное влияние, какие негативное, а какие не оказали влияния вовсе.

Какое мнение о России респондент транслирует своим согражданам. Вопросы 8, 11. Ответы на эти вопросы позволяют сделать вывод о том, что респондент считаем важным рассказать о России, выступает ли он в качестве распространителя мягкой силы России или нет.

Мнение о России соотечественников респондента. Вопросы 9, 10, 11,13 . Ответы на эти вопросы позволяют сделать вывод касательно мнения о России, которое распространено среди круга общения респондента. В круг общения студента входят как представители молодого поколения (друзья, знакомые), среднего поколения (родители и их друзья) и старшего поколения (бабушки, дедушки). В итоге мы получаем небольшой срез общественного мнения всех возрастных групп исследуемой страны.

Первым разберём интервью с представителями Южной Кореи. Один из респондентов находится в России чуть больше двух месяцев, второй - около 5 лет живет в России. Дальние родственники второго респондента живут в России, что повышает его симпатии к стране.

Общее отношение к России у респондентов положительное, оба приехали в нашу страну из интереса к русскому языку и нашей культуре. Восхищаются русской культурой и русским языком. Также одного из респондентов привлекла русская природа, её разнообразие и «нетронутость», большое количество животных, в частности, респондент отмечает то, что видел лисиц совсем близко. У него дома нет такой природы.

Получаемым образованием респонденты довольны. Один из респондентов отмечает, что до приезда в Россию считал русских людей злыми и Россию очень неприветливой страной. Но после нескольких недель пребывания здесь его мнение кардинально поменялось - он считает, что русские одни из самых дружелюбных и открытых людей и что русские более дружелюбны, чем его соотечественники. Оба респондента считают, что отношения между Россией и Южной Кореей вполне дружелюбные, у наших государств нет серьёзных противоречий и отношения между Россией и Южной Кореей значительно лучше, чем между Южной Кореей и Японией или Японией и Китаем. Оба респондента отмечают положительное отношение к внешней политике России. «Россия - сильная страна, которая может открыто выражать своё мнение. Это здорово. Корея маленькая и не может себе этого позволить», - говорит один из респондентов. Оба респондента особо высказываются о Путине. Один считает, что он достойный лидер и всегда отстаивает интересы своей страны, другой респондент говорит, что Путин - диктатор. Но при этом оба подчеркивают сильную позицию России на международной арене и говорят об этом уважительно.

Из минусов респонденты отмечают пробки во Владивостоке, большую бюрократию в самых разных процессах, плохо работающие 
сервисы по доставке, причем неважно, доставке чего именно - это касается любых сервисов доставки. Также к минусам отнесли и тараканов в общежитиях.

Респондент, который провел в России чуть больше двух месяцев, до приезда в Россию рассматривал вариант того, чтобы остаться жить в России, но из-за минусов, перечисленных выше, сейчас скептически смотрит на такую вероятность развития событий. Второй респондент рассматривает вариант остаться в России, открыть свой бизнес, но только при переезде в Москву.

Говоря о России со своими родственниками, один респондент чаще всего рассказывает о природе в России, а также о некоторых бытовых проблемах, с которыми он сталкивается в России. Оба респондента часто говорят с родственниками и друзьями о политике России, так как о России часто пишут в новостях и эта тема постоянно актуальна. Большинству друзей респондентов не очень интересна Россия, за исключением тех, кто также изучает русский язык. Если же разговор и заходит о нашей стране, то спрашивают либо что-то про русскую культуру, либо «про водку и медведей».

Также особым плюсом обучения в России один из респондентов называет тот факт, что здесь у него есть возможность пообщаться с гражданами Корейской Народно-Демократический Республики. У респондента уже был такой опыт, он оценивает его положительно и отмечает, что только благодаря обучению в России он может познакомиться с жителями Северной Кореи.

Оба респондента отмечают, что их соотечественники, которые являются молодыми людьми, не особо интересуются Россией, имеют общее представление и в общем довольно спокойно и «нейтральноположительно» относятся к России, потому что их не очень заботят политические проблемы и разногласия. Чего нельзя сказать о старшем поколении. Для многих пожилых корейцев Россия всё ещё ассоциируется с агрессивным Советским Союзом и коммунизмом и поэтому они относятся к России более негативно.

Таким образом, исходя из ответов южнокорейских респондентов можно сделать следующие выводы:

Молодёжь Республики Корея мало знает о России. Не считает Россию агрессором и поэтому внешнюю политику России воспринимает как сильную позицию страны на международной арене, а не агрессию.

Небольшой части молодёжи Кореи интересны русский язык и русская культура, у остальных нет чётких представлений о России и большого интереса к ней.

Старшее поколение южных корейцев относится к России негативно.

К особенностям России, которые интересны корейцам, можно отнести русскую нетронутую природу, которой сами корейцы лишены, а также возможность контакта с представителями КНДР на территории России.

Корейцы, обучающиеся в России, считают сервисы в России недостаточно развитыми и транслируют это мнение своим друзьям и знакомым. Но при этом российское образование оценивается хорошо.

В России проживает большое количество корейцев и эти диаспоры являются сильной стороной мягкой силы России, так как многие 
корейцы узнают о России и её культуре от своих родственников, проживающих здесь. Это позволяет говорить о серьёзном потенциале мягкой силы России в Южной Корее.

Для корейцев Россия - это всё ещё прежде всего Москва. И если связывать свою жизнь с Россией - то только в Москве, потому что Москва воспринимается как город с необходимым урбанистическим комфортом и возможностями. А также потому что в Москве значительное количество иностранных, в том числе корейских, компаний.

Далее рассмотрим интервью с представителями Японии. Один из них прожил в России полтора года, хочет выучить русский язык, хочет работать в качестве дипломата, второй пробыл в России три года, его отец работает в Санкт-Петербурге.

Общее впечатление о России у респондентов скорее положительное, они говорят, что относятся к нашей стране с симпатией. Вызывают интерес наш язык и культура. У одного респондентов вызывает интерес наш язык в том числе в силу того, что он считает Россию сильной страной на международной арене.

До приезда в Россию респонденты считали русских людей агрессивными и грубыми, но после жизни в России их мнение сильно изменилось. Они говорят о русских, как о самых дружелюбных и добрых людях, очень открытых, которые всегда готовы прийти на помощь. С большой симпатией относятся к русским людям. Отмечают, что в России они чувствуют себя в полной безопасности, ни разу за время своей жизни в России не сталкивались с преступностью. Также они были приятно удивлены тем, что не столкнулись в России с дискриминацией по отношению к азиатам.

Один из респондентов сказал, что «Россия живёт в прошлом веке» и мнение второго респондента также близко к этому высказыванию. Они говорят, что Россия сильно отстает в IT-технологиях от Японии и многие процессы можно было сделать проще и удобнее, используя цифровые технологии. Это сказывается и на образовательном процессе. Поэтому, хоть их и устраивает уровень знаний, который они получают касательно русского языка, сложно назвать их образование и жизнь в России «современными».

Оба готовы остаться работать и жить в России после окончания обучения, но только в иностранных компаниях, либо дипломатических ведомствах и только в Москве или Санкт-Петербурге.

Считают, что в России у государства, в том числе конкретно у Путина, слишком много власти и это мешает гражданам жить комфортно в своей стране.

При этом оба респондента относятся с симпатией к России и поэтому, когда заходят разговоры с их родственниками или друзьями о России, они в какой-то степени защищают нашу страну. Например, один из респондентов считает, что Путин не настолько плохой и жестокий правитель, как о нём думают в Японии, хоть и, несомненно, диктатор. Другой своими постами в социальной сети Facebook старается убедить японцев, что Россия им не враг.

Оба респондента считают, что отношения между нашими странами плохие, основная причина - территориальный спор между государствами. При этом один из респондентов, который стремится стать дипломатом, считает, что настоящей причиной плохих взаимоотношений между Россией и Японией является сильная зависи- 
мость Японии от США. «Япония как послушная американская собачка», - говорит он. Если бы Япония не была так зависима от США, то Япония, скорее всего, легко бы отказалась от своих территориальных претензий и между нашими странами получилось бы наладить хорошие отношения.

Большинство друзей респондентов, живущих в Японии, имеют слабое представление о России, считают, что она просто «холодная». Многие из них думают, что русские люди агрессивны и много пьют водку. Некоторые из них хотят побывать в России из интереса к нашей культуре и желания «сфотографироваться с медведем». Один из респондентов говорит, что «молодёжь Японии знает, что в России есть милые девушки и красивые города. А некоторые даже знают Гошу Рубчинского [2], который играет большую роль в мире моды».

Старшее поколение японцев крайне негативно относится к России. Для одних Россия - это Советский Союз, коммунизм и военная агрессия, особенно это относится к жителям Хоккайдо, так как спорные территории между Россией и Японией относятся к губернаторству Хоккайдо. Для других Россия - это страна балета и великой классической культуры, которая остается жестокой диктатурой и действует на международной арене нечестным образом. И те, и другие считают Россию и русских агрессивными, жестокими и не заслуживающими доверия. Россия в Японии непопулярна.

Исходя из ответов респондентов, которые являются гражданами Японии, можно сделать следующие выводы:

Россия для японцев, как и для корейцев, - это прежде всего Москва, и если они и согласны остаться в России, то только в Москве или Санкт-Петербурге по тем же причинам, что и корейцы.

В Японии существует устойчивое представление о русских как о жестоких, агрессивных и грубых людях.

Старшее поколение Японии знает и уважает российскую культуру, особенно балет. Но также старшее поколение японцев считает Россию агрессивной, нечестной страной, которой правит жестокий диктатор.

У молодёжи нет такого негативного отношения к России, как у старшего поколения. Да, нельзя сказать, что японская молодежь с симпатией относится к России, но отношение молодых японцев к нашей стране более спокойное, чем у старшего поколения. При этом молодые японцы очень мало знают о России в целом и о нашей культуре в частности.

Японцы, обучающиеся в России, проникаются симпатией к России и стараются убедить своих соотечественников в том, что Россия не такая уж и плохая.

В представлении японцев Россия - страна, которая сильно отстала в IT-технологиях. И те японцы, которые обучаются в России, поддерживают это мнение.

Последним рассмотрим интервью с представителями КНР. Один из них проживает в России два года, второй - четыре года. Оба респондента допускают возможность остаться жить и работать в России, в том числе на Дальнем Востоке.

Общее впечатление о России у обоих респондентов положительное. Один приехал изучать русский язык и русскую культуру, второй - обучается на врача. Выбрал Россию, потому что с детства много 
слышал о нашей стране, так как у него проживают родственники в Хабаровске.

Очень хорошее отношение к русским людям. Оба респондента отмечают, что русские очень открытые и искренние люди, которые ценят любовь и дружбу. Один из респондентов говорит, что «если у тебя появился друг из России, то эта дружба будет крепкой и долгой».

При этом оба респондента из минусов называют тот факт, что в России люди очень медленно работают, постоянные очереди в различных местах. В Китае такого нет, они к этому не привыкли, и этот факт влияет негативно на их мнение о России.

Получаемым образованием оба респондента довольны, хотя и отмечают тот факт, что иногда за преподавателем нужно «бегать», чтобы получить консультацию. В Китае преподаватели более терпеливые и стараются ответить на все вопросы студентов и каждому уделить внимание.

У респондентов и их друзей и родственников уважительное отношение к русской культуре, особенно к литературе. Респондент отмечает особую любовь к Достоевскому как у себя, так и среди своих знакомых. Также среди старшего поколения популярны советские песни. Респондент даже знает часть песни «Катюша» наизусть.

Респонденты говорят, что в китайском обществе существует очень устойчивое представление о русских, как о «нации воинов». Что русские жесткие и смелые люди, которые привыкли постоянно сражаться. Это представление разделяют как старшее, так и младшее поколение.

И старшее, и младшее поколения китайцев из числа знакомых респондентов с симпатией относятся к России, хотя молодёжь крайне мало знает о России. Один из респондентов говорит, что если его друзьям предоставить выбор, поехать в качестве туриста в Россию или в Европу, то многие выберут Европу, просто потому что они мало знают о России. Старшее поколение очень хорошо относится к России, для них Россия - это СССР, а СССР - это старший брат, который всегда помогал Китаю. И тот факт, что сегодня Россия и КНР тесно сотрудничают, только усиливает хорошее отношение китайцев к нашей стране.

Респонденты со своими родственниками, иногда с друзьями, когда обсуждают Россию, преимущественно говорят о внешней политике и Владимире Путине. Они одобряют внешнюю политику нашей страны и считают Путина сильным и хорошим правителем.

Исходя из ответов респондентов, которые являются гражданами Китая, можно сделать следующие выводы:

В китайском обществе сформировалось представление о России, как о сильной, воинственной нации, которая долгое время, с середины прошлого века, является другом Китая. России.

Несмотря на это, китайская молодежь довольно мало знает о

Китайцы, которые обучаются в России, рассматривают вариант остаться работать и жить в нашей стране, в том числе на Дальнем Востоке.

По мнению китайцев, находящихся в России, в нашей стране плохо работают сервисные организации. 
В китайском обществе существуют исторически обусловленные уважение и интерес к русскому языку и культуре. Особенно к литературе и музыке.

Позитивный образ России в Китае сложился за счёт коммунистического прошлого России и действий СССР, а так как сегодняшняя Россия ведет себя на международной арене сходным образом и также является другом Китая - этот образ только укрепляется.

Таким образом, можно говорить о том, что обучение в Дальневосточном федеральном университете делает граждан Японии, КНР и Республики Корея более лояльными по отношению к России, за счёт более близкого и глубокого знакомства с Россией и россиянами. Но активными «проводниками» положительного имиджа России в своих странах они не становятся, потому что в отношении них не ведётся соответствующая деятельность, что является серьёзным упущением. В условиях, когда молодёжь Японии и Южной Кореи мало знает о России, необходимо воспользоваться имеющимися у российского высшего образования ресурсами, чтобы формировать у молодых людей Японии, Южной Кореи и Китая привлекательный образ России, за счёт положительного опыта их соотечественников, которые обучаются в России.

\section{Литература}

1. Пименова Е. В. Закат «Мягкой силы»? Эволюция теории и практики soft power // Вестник МГИМО-Университета. 2017. № 1 (52). C. 57-66.

2. Gosha Rubchinskiy [Электронный документ] // Business of Fashion (сайт). URL https://www.businessoffashion.com/ community/people/gosha-rubchinskiy-1 (дата обращения: 10.10. 2020).

3. Members of APRU [Электронный документ] // Association of Pacific Rim Universities (сайт). URL https://apru.org/ members/ (дата обращения: 11.10.2020).

4. Nye J. Bound to Lead: The Changing Nature of American Power.- Basic Books, 1990. $307 \mathrm{p}$.

5. World Bank national accounts data, and OECD National Accounts data files [Электронный документ] // World Bank (сайт). URL https://data.worldbank.org/indicator/ NY.GDP.MKTP.CD? end = $2018 \&$ most_ recent_value_desc $=$ true\&start $=1960 \&$ view $=$ chart\&year_high_desc=true (дата обращения: 11.10.2020). 


\section{Ruslan A. GRITSENKO}

Graduate Student, Oriental Institute - School of Regional and International Studies, Far Eastern Federal University (Vladivostok, Russia)

E-mail: gritcenko.ra@dvfu.ru

\section{Evaluation of Russian Soft Power in China, Japan and South Korea Using Qualitative Methods (on the Example of in-depth Interviews with FEFU Foreign Students)}

\section{UDC 327.8}

international relations, soft power,

Northeast Asia, higher education, Russia's image in Northeast Asia, in-depth interviews with foreigners

\author{
doi: dx.doi.org/10.24866/2542-1611/2020-3/70-78
}

The present article is devoted to the state of Russian soft power in countries of North-East Asia. The author analyzes the perception of Russia by Japanese, Chinese, and South Korean students studying at the Far Eastern Federal University, as well as by their environment. The main research method is conducting in-depth interviews with the students themselves. Based on the results of the interview, several conclusions were formed regarding the state of soft power of the Russian Federation in this country. Also, the author puts an emphasis on several general conclusions, namely: studying in Russia has a positive impact on the opinion about the country, but at the same time there is a rather vague idea of Russia in Japan and South Korea, and thus active work needs to be deployed in this direction.

For citation: Gritsenko R. A. Evaluation of Russian Soft Power in China, Japan and South Korea Using Qualitative Methods (on the Example of in-depth Interviews with FEFU Foreign Students) // Oriental Institute Journal. 2020. № 3. P. 70-78. doi: dx.doi.org/10.24866/2542-1611/2020-3/70-78

\section{References}

1. Pimenova E. V. Zakat «Myagkoj sily»? EHvolyutsiya teorii i praktiki soft power // Vestnik MGIMO-Universiteta. 2017. № 1 (52). S. 57-66.

2. Gosha Rubchinskiy [EHlektronnyj dokument] // Business of Fashion (sajt). URL https://www.businessoffashion.com/ community/people/gosha-rubchinskiy-1 (data obrashheniya: 10.10. 2020).

3. Members of APRU [EHlektronnyj dokument] // Association of Pacific Rim Universities (sajt). URL https://apru.org/ members/ (data obrashheniya: 11.10.2020).

4. Nye J. Bound to Lead: The Changing Nature of American Power.- Basic Books, 1990. $307 \mathrm{p}$.

5. World Bank national accounts data, and OECD National Accounts data files [EHlektronnyj dokument] // World Bank (sajt). URL https://data.worldbank.org/indicator/ NY.GDP.MKTP.CD? end $=2018 \&$ most_ recent_value_desc $=$ true $\&$ start $=1960 \& v$ iew $=$ chart\&year_high_desc=true (data obrashheniya: 11.10.2020). 